\title{
PPAR Gamma agonists regulate tobacco smoke-induced toll like receptor 4 expression in alveolar macrophages
}

Yan Yin, Gang Hou, Erran Li, Qiuyue Wang* and Jian Kang

\begin{abstract}
Background: Peroxisome proliferator-activated receptor-gamma (PPARY) is a ligand-activated transcription factor that exerts multiple biological effects. Growing evidence suggests that PPARY plays an important role in inflammation; however, the effects of this transcription factor on the inflammation caused by smoking are unclear.

Methods: We measured the expression of inflammatory cytokines (leukotriene B4, LTB4 and interleukin 8, IL-8), PPARY and toll-like receptors (TLR2 and TLR4) in alveolar macrophages (AMs) harvested from rats exposed to cigarette smoke (CS) for 3 months in vivo. Some of the rats were pre-treated with rosiglitazone (PPARY agonist, $3 \mathrm{mg} / \mathrm{kg} / \mathrm{day}$, ip), rosiglitazone (3 mg/kg/day, ip) + BADGE (bisphenol A diglycidyl ether, a PPARY antagonist, 30 mg/kg/day, ig), or BADGE alone (30 mg/kg/ day, ig). We also measured the expression of PPARY, TLR2, TLR4 and nuclear factor-kappaB (NF-kB) in AMs gained from normal rats, which exposed to 5\% CSE (cigarette smoke extract) for 12hrs, respectively pretreated with PBS, rosiglitazone (30 uM), rosiglitazone (30 uM) + BADGE (100 uM), 15d-PGJ2 (PPARy agonist, 5 uM), 15d-PGJ2 (5 uM) + BADGE (100 uM), or BADGE (100 uM) alone for $30 \mathrm{~min}$ in vitro.
\end{abstract}

Results: In vivo, rosiglitazone counteracted CS-induced LTB4 and IL-8 release and PPARy downregulation, markedly lowering the expression of TLR4 and TLR2. In vitro, both rosiglitazone and 15d-PGJ2 inhibited CS-induced inflammation through the TLR4 signaling pathway.

Conclusions: These results suggest that PPARY agonists regulate inflammation in alveolar macrophages and may play a role in inflammatory diseases such as COPD.

Keywords: Peroxisome proliferator-activated receptor $\gamma$, Cigarette smoke, Toll-like receptors, Alveolar macrophages, Nuclear factor-kappa B

\section{Background}

Chronic obstructive pulmonary disease (COPD) is a chronic inflammatory disease of the airways that is characterized by progressive limitations in airflow. Cigarette smoking is one of the most important risk factors for COPD and persistent airway inflammation [1]. Eliminating the inflammation caused by cigarette smoke (CS) is a goal of COPD treatments. Peroxisome proliferator-activated receptor gamma (PPAR $\gamma$ ), a member of the nuclear hormone receptor superfamily [2], has been identified in lung tissue and the cells associated with inflammation in the lung [3-5]. Therefore, PPARY agonists may be the next choice

\footnotetext{
* Correspondence: qywang2002@hotmail.com

Institute of Respiratory Disease, The First Affiliated Hospital of China Medical University, Shen Yang City, China
}

\section{() Biomed Central}

for COPD treatment. Recent studies have shown that PPARY expression is reduced in the skeletal muscles, airways, and alveolar macrophages (AMs) of individuals suffering from chronic pulmonary diseases. Recently, the studies have shown increased PPAR $\gamma$ expression in the bronchial epithelial cells of asthma patients, but decreased PPARy expression in allergic inflammation and acute lung injury induced by LPS [6-8]. Moreover, thiazolidinediones exert anti-inflammatory effects by activating PPAR $\gamma$ and downregulating nuclear factor- $\mathrm{kB}(\mathrm{NF}-\kappa \mathrm{B})[9,10]$. These results have led to increasing interest in PPAR $\gamma$ and its involvement in a variety of disease states, including COPD.

While PPAR $\gamma$ agonists exhibit anti-inflammatory effects, the effect of these molecules in CS-induced chronic inflammation is largely unknown. AM-mediated inflammation 
Table 1 Primers for gene-specific reverse transcription and real-time polymerase chain reaction (in vivo test and in vitro test)

\begin{tabular}{ccc}
\hline Gene & Forward primer & Reverse primer \\
\hline PPARY & ATTCTGGCCCACCAACTTCGG & TGGAAGCCTGATGCTITATCCCCA \\
TLR2 & GTCCATGTCCTGGTTGACTGG & GATACCACAGCCCATGGAAAT \\
TLR4 & GAGCCGGAAAGTTATTGTG & AGCAAGGACTTCTCCACTTCT \\
$\beta$-actin & GCCAACCGTGAAAAGATG & CCAGGATAGAGCCACCAAT \\
\hline
\end{tabular}

plays a critical role in the development of COPD [11,12], and the engagement of Toll-like receptors (TLRs) can trigger AMs to produce inflammatory mediators [13]. Some anti-inflammatory mediators reduce airway inflammation through the TLR2/TLR4 pathway [14], but little is known about the interaction between the TLR2/TLR4 pathway and the anti-inflammatory PPARy pathway. Given these considerations, we sought new insight into the role of PPAR $\gamma$ agonists in preventing chronic airway inflammation and impairing the AM response to CS. To gain a better understanding of the PPARY mechanism of action in AMs, we also investigated the effects of PPAR $\gamma$ agonists on the expression of TLR2, TLR4 and NF-kB. Additionally, we investigated whether BADGE, a PPAR $\gamma$ antagonist, attenuates the protective effect of PPAR $\gamma$ agonists.

\section{Methods}

\section{Animals and experimental design}

All of the experiments were conducted in accordance with ethical committee guidelines. As shown as Additional file 1: Figure S1, male Wistar rats (Laboratory Animal Center, China Medical University) with a weight range of 170-220 g were randomly placed into one of five groups of 12 rats: sham, CS, PPAR $\gamma$ agonist rosiglitazone (ROSI), PPAR $\gamma$ antagonist BADGE (BADGE), and ROSI + BADGE (RB). The rats were sacrificed by exsanguination before excision of the lungs at the end the 12th week. The right upper lobes were removed and stored at $-80^{\circ} \mathrm{C}$.

\section{Tissue preparation and morphometric analyses}

The middle lobes of the right rat lungs, which were not lavaged, were embedded in paraffin blocks, and sectioned at $4-\mu \mathrm{m}$ thickness for conventional HE staining. The measure of lung tissue morphology was determined by light microscopy at a magnification of $\times 200$. At least two nonconsecutive slides per block were analysed for the following: (i) mean linear intercept (MLI), which was a measure of interalveolar wall distance, defined by the total length of the cross-line divided, by the numbers of alveolar wall intersecting the test lines; (ii) mean alveolar number (MAN), which was an indicator of alveolar density calculated by counting the numbers of alveoli in each field.

\section{Isolation and culture of alveolar macrophages}

The left lungs were infused with $2 \mathrm{ml}$ PBS for 4 times. The bronchoalveolar lavage fluid (BALF) was centrifuged for 10 $\mathrm{min}$ at $1000 \mathrm{r} / \mathrm{min}$ and $4^{\circ} \mathrm{C}$. The pellets obtained from the BALF were washed twice with cold Phosphate Buffered Saline (PBS) and resuspended in PBS at $1 \times 106$ cells $/ \mathrm{ml}$. The cells were then incubated in 6-well plates in $2 \mathrm{ml}$ RPMI1640 medium with $10 \%$ fetal calf serum (FCS). All of the nonadherent cells were removed by washing with PBS. We used a previously described modified H\&E staining method [15] to identify alveolar macrophages (AMs) based on morphology. The purity of the cell suspension was $>95 \%$.

\section{Phagocytosis and viability of alveolar macrophages}

AMs were harvested from the BALF of different groups, and $2 \times 10^{5} \mathrm{AMs} /$ well were cultured in RPMI-1640 for 3 hrs or 24 hrs. Phagocytosis was measured with the neutral red uptake method described in previous article [16]. All of the nonadherent cells were removed by washing with PBS. The adherent cells were incubated in $100 \mu \mathrm{L}$ of RPMI-1640 and $100 \mu \mathrm{L}$ of neutral red $(0.072 \%)$ reagent for 4 hrs. The plates were then washed to remove the excess dye and blotted dry. The incorporated dye was re-suspended in ethanol (50\%) containing glacial acetic acid (1\%). Subsequently, the absorbance at OD490 was read using a spectrophotometer. The absorbance $(\mathrm{A})$ was translated into a phagocytosis ratio to make comparisons: phagocytosis ratio $=$ test $\mathrm{A} /$ normal control A $\times 100 \%$.

For the metabolic activity assays in vivo, AMs gained from each group were cultured in 96-well plates at a density of $1 \times 10^{5}$ cells/well. AMs were stimulated with 5\% CSE in RPMI-1640 with 10\% FCS for 4 hrs in a humidified atmosphere of $5 \% \mathrm{CO}_{2}$ and $37^{\circ} \mathrm{C}$. After

Table 2 BAL Fluid cytology of rats of each group

\begin{tabular}{lcccc}
\hline Group & Sum $(\times$ 106/L) & Lymphocytes \% & Macrophages \% & Neutrophils \% \\
\hline Sham & $3.8 \pm 1.44$ & $3.8 \pm 1.63$ & $88.5 \pm 9.43$ & $2.91 \pm 1.92$ \\
CS only-exposed & $13.4 \pm 3.29^{* *}$ & $9.6 \pm 3.45^{* *}$ & $66.8 \pm 10.66^{* *}$ & $20.4 \pm 9.44^{* *}$ \\
ROSI-treated & $9.3 \pm 2.66^{* * \#}$ & $6.7 \pm 2.20^{*}$ & $76.9 \pm 6.34^{* *}$ & $11.5 \pm 3.14^{* * \#}$ \\
BADGE-treated & $13.4 \pm 3.37^{* *}$ & $9.07 \pm 3.16^{* *}$ & $68.5 \pm 10.16^{*}$ & $20.5 \pm 8.66^{* *}$ \\
RB-treated & $11.5 \pm 2.06^{* * \# \#}$ & $7.8 \pm 2.69^{* *}$ & $69.1 \pm 7.06^{* *}$ & $19.9 \pm 4.16^{* *}$ \\
\hline
\end{tabular}

Data represent the mean $\pm S D(n=6) . * P<0.05$ and ${ }^{* *} P<0.01$ compared with the sham group; $\# P<0.05$ and $\# \# P<0.01$ compared with the CS only-exposed group. 


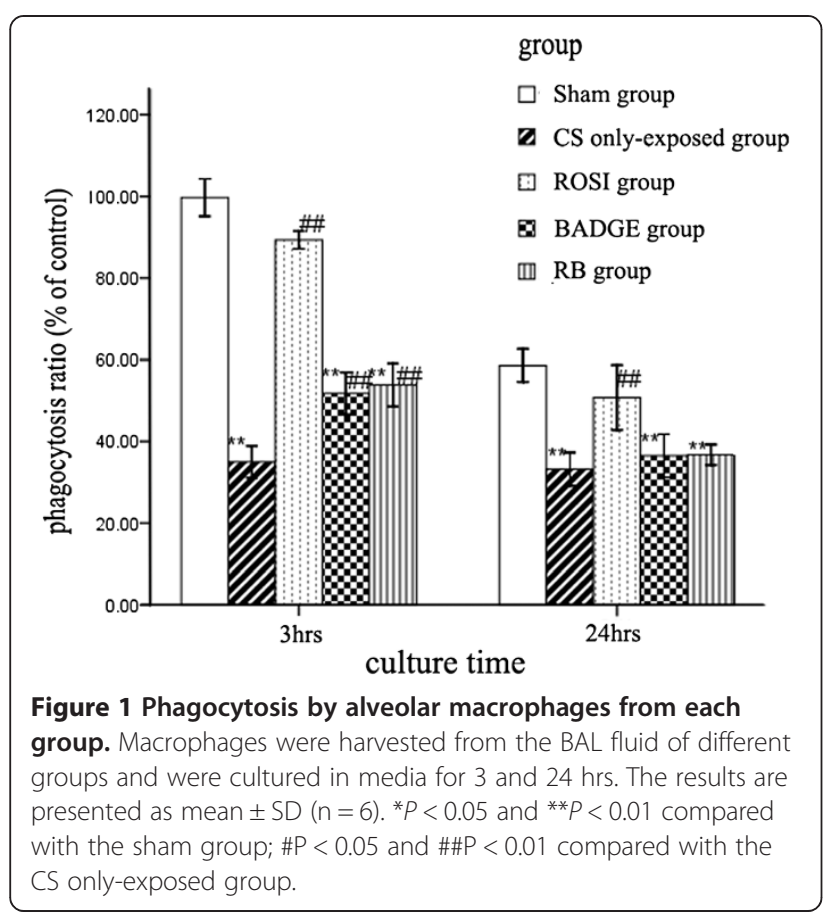

treatment, the medium was discarded and $200 \mu \mathrm{L}$ of DMEM containing $20 \mu \mathrm{L}$ of MTT (methylthiazolyldiphenyl-tetrazolium bromide, $5 \mathrm{mg} / \mathrm{mL}, \mathrm{pH}=7.4$ ) reagent was added to each well. The cells were incubated for 4 hrs at $37^{\circ} \mathrm{C}$. The medium was again discarded, DMSO was added to each well, and the MTT activity was measured at an optical density of $570 \mathrm{~nm}$. The absorbance (A) was translated into a viability ratio to make comparisons: viability ratio $=$ test $\mathrm{A} /$ normal control $\mathrm{A} \times 100 \%$.

For the metabolic activity assays in vitro, AMs gained from normal rats were stimulated with 1\% CSE (cigarette smoke extract), 5\% CSE and 10\% CSE individually for 6 hrs. The cells were pretreated with PBS, ROSI $(30 \mu \mathrm{M})$, ROSI $(30 \mu \mathrm{M})+$ BADGE $(100 \mu \mathrm{M})$ (BADGE was administered 30 min before ROSI), 15-deoxy- $\Delta$ prostaglandin J2 (15d-PGJ2, a natural ligand of PPARy, $5 \mu \mathrm{M}$ ) or 15d-PGJ2 $(5 \mu \mathrm{M})+$ BADGE $(100 \mu \mathrm{M})$, (Sigma-Aldrich Corporation, St. Louis, MO, USA) for $30 \mathrm{~min}$ before being treated with different concentration of CSE.

\section{Immunofluorescence staining of TLR2 and TLR4 in AMs}

The sections was incubated with 5\% BSA in PBS at room temperature for $60 \mathrm{~min}$, and then incubated with primary rabbit anti-rat TLR4 and anti-rat TLR2 antibodies (1:300, Santa Cruz, CA, USA) at $4^{\circ} \mathrm{C}$ overnight. The primary antibody was detected with biotinylated anti-rabbit Ig at a 1:200 dilution. Bound antibody was visualized with $A B C$ peroxidase. Images were obtained with a confocal microscope (Olympus, Japan). The images were quantified by analyzing the sum of the staining with Metamorph DP10 (Olympus, Japan). The negative controls that received PBS were run in parallel. The endogenous peroxidase activity of the AMs treated with cigarette smoke extract in vitro was detected using the same protocol described above.

\section{Stimulation of AMs with CSE and the culture of AMs with ROSI, BADGE and 15dPGJ2}

The CSE was prepared as follows: 2 filtered cigarettes (3R4F), each described by the manufacturer as containing $0.73 \mathrm{mg}$ of nicotine, $9.4 \mathrm{mg}$ of tar, and $12.0 \mathrm{mg}$ of $\mathrm{CO}$, were bubbled through $20 \mathrm{ml}$ serum free RPMI-1640 medium with a mechanical vacuum pump. The extract was filtered through a $0.45-\mu \mathrm{m}$ filter (Millipore, Bedford, MA, USA) to remove bacteria and particles. CSE concentration was evaluated by measuring the optical density at $502 \mathrm{~nm}$, and diluted to O.D. $=0.17 \pm 0.03$. This solution was considered $10 \%$ CSE.

The AMs harvested from the normal rats. The normal AMs were stimulated with 1\% CSE, 5\% CSE and 10\% CSE individually for $12 \mathrm{hrs}$, after which we analyzed the changes in TLR2, TLR4 and PPAR $\gamma$ expression, the release of LTB4 and IL-8 into the cell culture supernatant and the viability of the AMs. The cells pretreated with ROSI $(30 \mu \mathrm{M})$, ROSI $(30 \mu \mathrm{M})+$ BADGE $(100 \mu \mathrm{M})$ (BADGE was administered $30 \mathrm{~min}$ before ROSI), 15dPGJ2 $(5 \mu \mathrm{M}), 15 \mathrm{~d}-\mathrm{PG}) 2(5 \mu \mathrm{M})+$ BADGE $(100 \mu \mathrm{M})$, or PBS for $30 \mathrm{~min}$ before being treated with 5\% CSE for $12 \mathrm{hrs}$. We further investigated the above-mentioned parameters in the presence or absence the NF- $\mathrm{KB}$ inhibitor PDTC $(10 \mu \mathrm{mol} / \mathrm{L})$ (Sigma-Aldrich Corporation, St. Louis, MO, USA). In addition, We detected the secretions of LTB4 and IL-8 into the cell culture supernatant, when the cells co-treated with anti-mouse specific

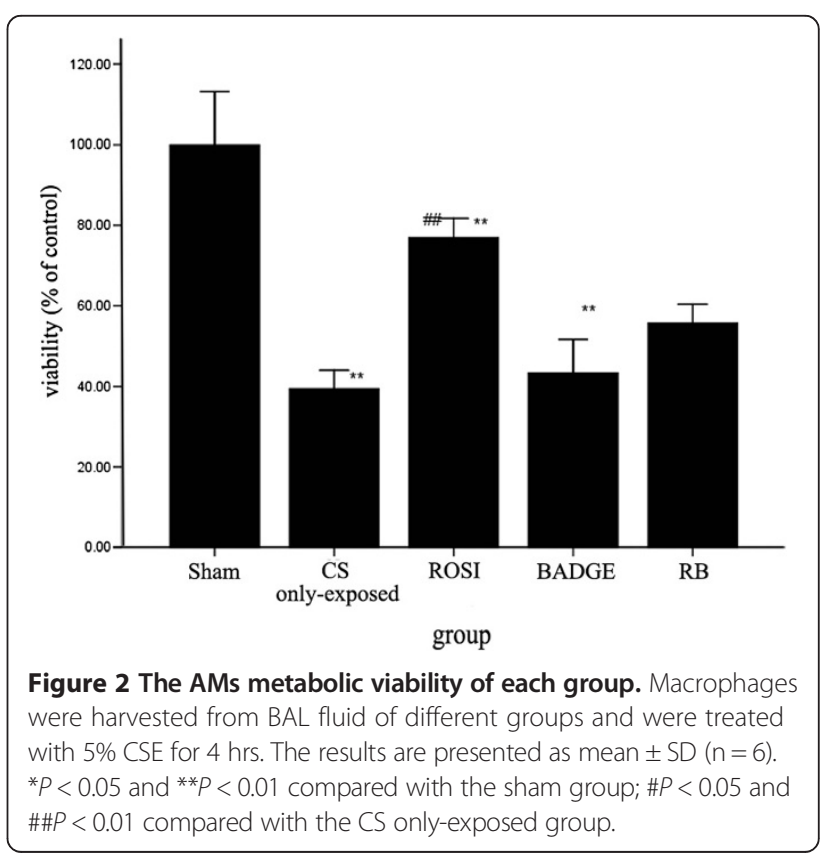



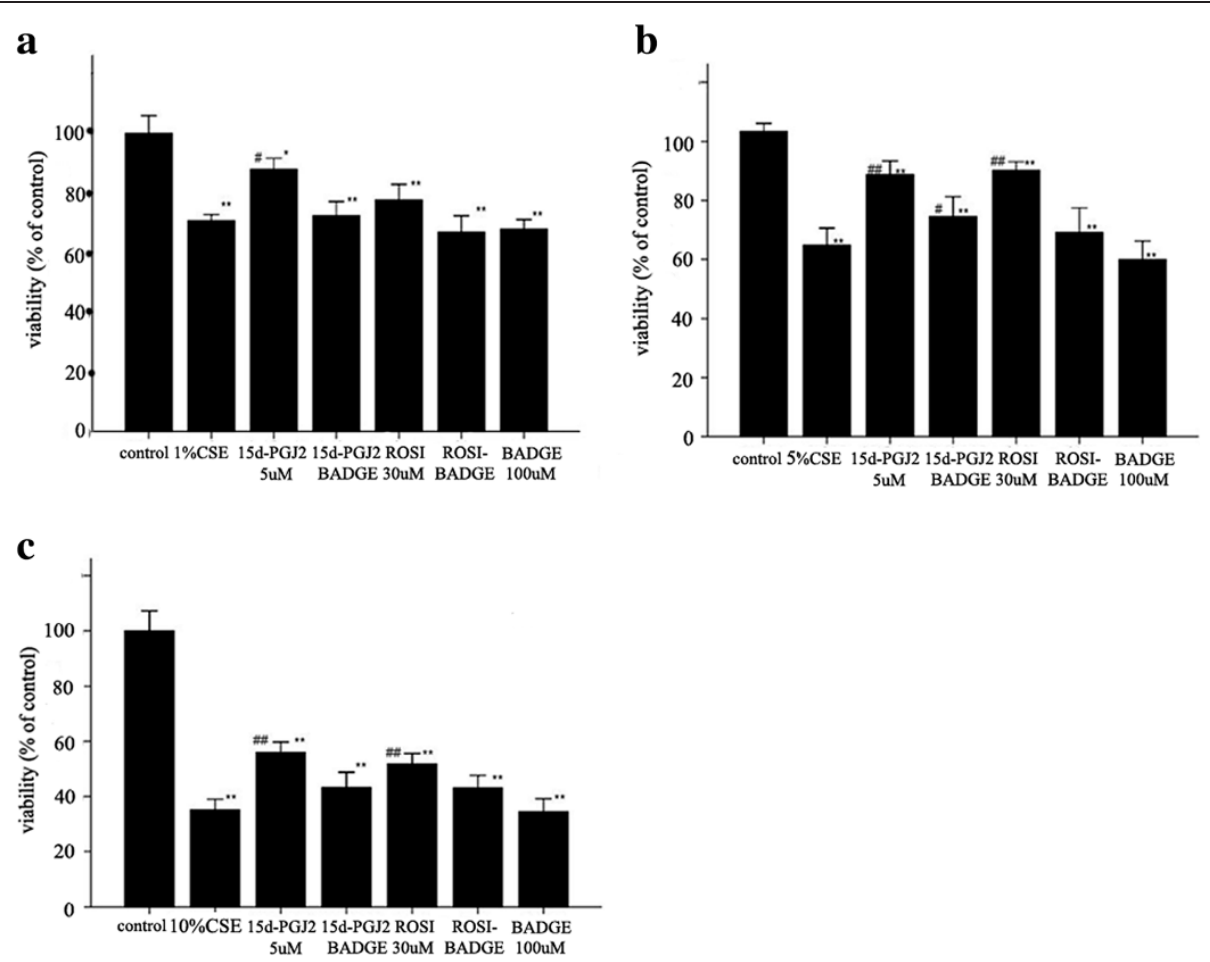

Figure 3 The metabolic viability test in vitro. AMs gained from normal rats were stimulated with 1\% CSE (a), 5\% CSE (b) and 10\% CSE (c) individually for $4 \mathrm{hrs}$. The AMs in response to different drug pretreatment interventions. The results are presented as $m e a n \pm S D(n=3)$. ${ }^{*} P<0.05$ and ${ }^{* *} P<0.01$ compared with the control group; $\# P<0.05$ and \#\#P<0.01 compared with the CSE group.

antibody for TLR4 (eBioscience, San Diego, CA, USA) and $5 \%$ CSE.

\section{Real-time PCR analysis for measurement of TLR2, TLR4 and PPARY}

Total RNA was prepared from AMs, using Trizol according to the manufacturer's instructions. PCR was carried out with the One-Step qRT-PCR kit (TaKaRa Co, Dalian, China) performed on an ABI PRISM 7500 instrument (ABI, Foster City, CA, USA.), following the manufacturer's instructions. Primers for PPAR $\gamma$, TLR2, TLR4 and $\beta$-actin using gene-specific primers (Table 1). The PCR parameters were initial denaturation at $94^{\circ} \mathrm{C}$ for $2 \mathrm{~min}$, followed by 40 cycles of $94^{\circ} \mathrm{C}$ for $30 \mathrm{~s}$ and $72^{\circ} \mathrm{C}$ for $60 \mathrm{~s}$. Gene expression was quantified using a comparative critical threshold (CT) method as described previously [17].

\section{Flow cytometric analysis of the surface expression of TLR2 and TLR4 in AMs}

Frozen AMs were washed with PBS and pelleted by centrifugation $\left(800 \mathrm{rpm}\right.$ for $5 \mathrm{~min}$ at $4^{\circ} \mathrm{C}$ ). The samples were resuspended at $1 \times 10^{6}$ cells $/ 2 \mathrm{ml}$ RPMI-1640 medium, after which a fluorescein isothiocyanate (FITC)-conjugated antirat TLR2 $\mathrm{mAb}$ and a TLR4 mAb were added to the cells for $60 \mathrm{~min}$ on ice, as instructed by the manufacturer. The cells were then analyzed with FACS and Cell Quest software.

\section{ELISA for measurement of IL-8 and LTB4 in Bal fluid and culture supernatants}

The expressions of interleukin-8 (IL-8) and leukotriene B4 (LTB4) in BAL fluid and culture supernatants were determined using the QuantiGlo ET-1 Immunoassay System (BD Biosciences, Bedford, MA), according to the manufacturer's protocol. BCA (bicinchoninic acid) protein assay was used to correct the homogenate supernatants of $50 \mathrm{mg}$ lung tissues in the different groups as measured by enzyme-linked immuno sorbent (ELISA).

\section{Western blot analysis for PPAR $\gamma$, TLR4, NF-KB}

$20 \mu \mathrm{g}$ of isolated total protein was subjected to electrophoresis on a $10 \%$ polyacrylamide (PAGE) gel and transferred onto a nitrocellulose membrane by electroblotting. The membrane was blocked for 1 hrs at room temperature with blocking solution. The blot was then incubated overnight at $4^{\circ} \mathrm{C}$ with rabbit anti- PPAR $\gamma$, anti-TLR4, anti-I- $\mathrm{B}$ or antiP65 antibody (1:500; Santa Cruz Biotechnology, Santa Cruz, CA, USA). After three washing steps, the membrane was incubated with secondary antibody (1:2000 dilution) for $2 \mathrm{hrs}$ at room temperature. Bound complex was detected using enhanced chemiluminescence (Amersham 


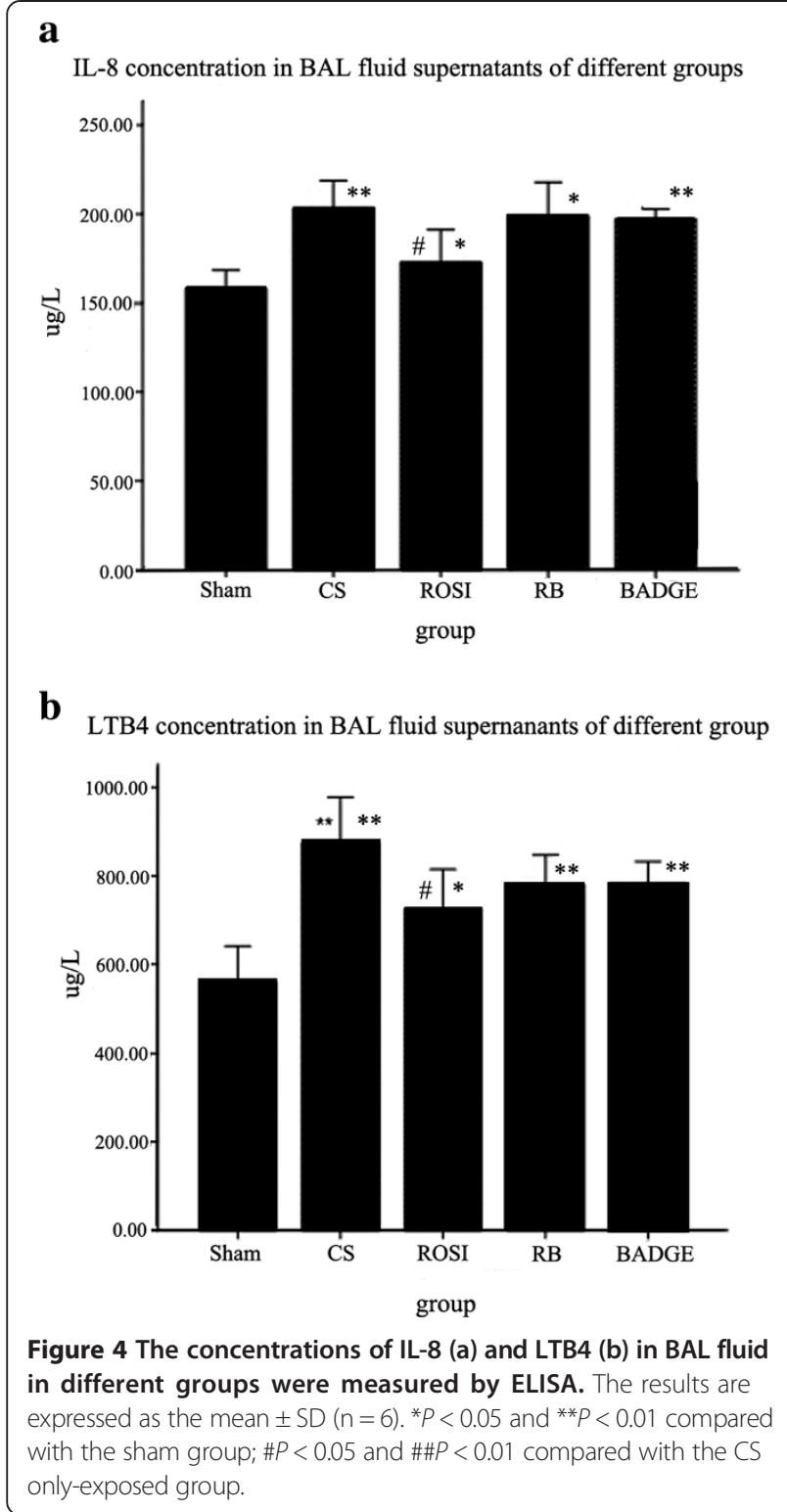

Biosciences, NJ, USA). Densitometric techniques were performed to quantify the protein band densities (Metamorph/ Evolution MP 5.0/B $\times 51$ ), which were expressed as mean relative densitometric units.

\section{Results}

ROSI attenuated CS induced histological changes

CS exposure induced airway inflammation accompanied by focal emphysema. First, the airway wall may have been thickened by inflammatory cell infiltrates or structural changes. Second, the airway lumen was occluded by mucous secretions. Third, alveolar attachments became disrupted as a result of emphysema. The sham group displayed no discernible histological
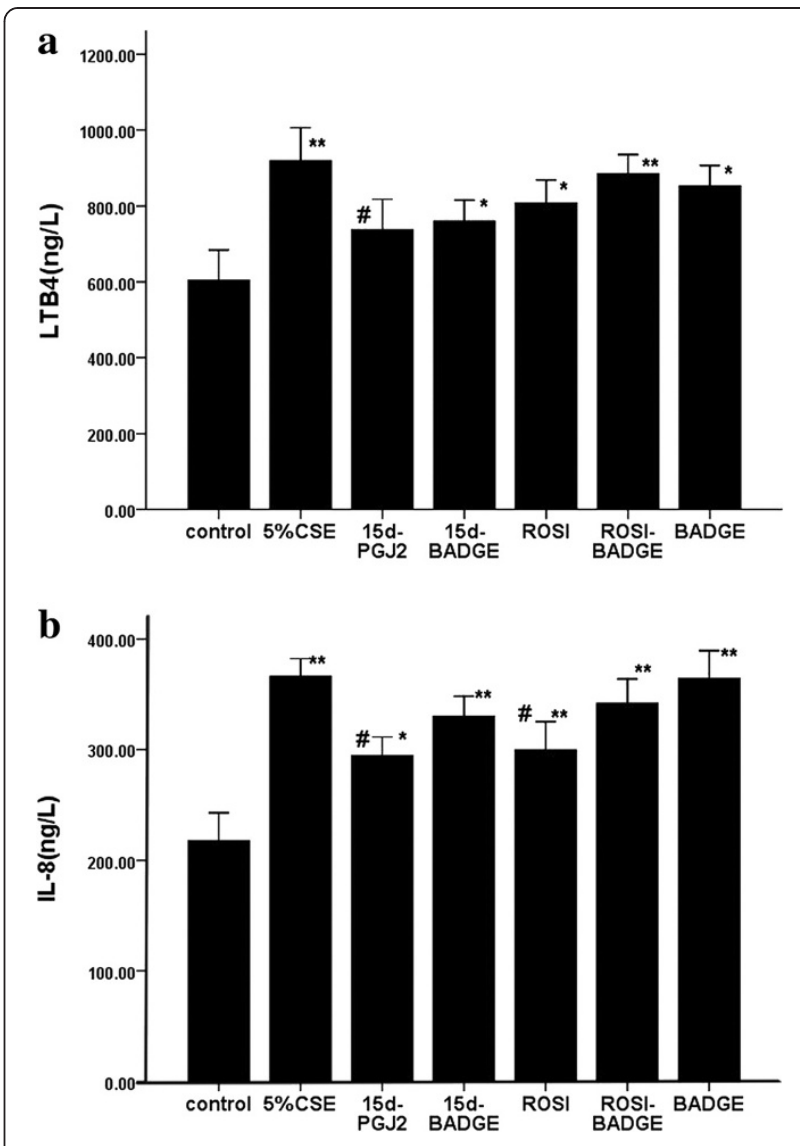

Figure 5 Cell Supernatants were harvested to measure LTB4 (a) and IL-8 (b) by ELISA. The results are expressed as the mean \pm SD $(n=3) .{ }^{*} P<0.05$ and ${ }^{*} P<0.01$ compared with the sham group; $\# P<0.05$ and \#\#P<0.01 compared with the CSE group.

changes. The ROSI exhibited a protective effect on emphysematous changes and airway inflammation induced by CS exposure. And these effects were partially attenuated by BADGE. Moreover, there was no difference between CS group and BADGE groups. (Additional file 1: Figure S2, Figure S3 and Table S1).

\section{ROSI reduced the number of inflammatory cells present} in the BALF after CS exposure

As shown in Table 2, CS generally increased the counts of total cells, neutrophil \%, lymphocytes \% and the number of AMs, and decreased AMs \% count. Compared to CS group, ROSI- treatment induced the reductions of the counts of total cells and neutrophiles \%. ROSItreatment tended to attenuate the reduction of AMs \% induced by $\mathrm{CS}$ exposure, however, none of differences were statistically significant $(P=0.06>0.05)$. There was no significant difference between the BADGE- treated and the CS only groups. 
Effects of PPARY ligands on the phagocytosis and viability of AMs

In vivo, the AMs from the groups exposed to CS exhibited decreased phagocytosis (Figure 1) and viability (Figure 2). The AM-mediated phagocytosis at $3 \mathrm{hrs}$ and $24 \mathrm{hrs}$ showed similar changes: the ROSI-treated group showed an increase in phagocytosis and metabolic viability compared with the CS group, while BADGE partially blocked the ROSI-induced recovery in both phagocytosis and cell viability. The effects of the combined ROSI plus BADGE treatment on phagocytosis and cell viability were similar to the effects of treatment with BADGE alone.

Likewise, the AMs in the primary culture presented similar results in vitro. Both 15d-PGJ2 and ROSI attenuated the decrease in cell viability induced by $1 \%$, $5 \%$ and $10 \%$ CSE. And pre-treatment with BADGE counteracted the protective effect of 15d-PGJ2 and ROSI in vitro (Figure 3).

\section{PPAR $\gamma$ ligands decreased CS-induced inflammatory cytokine production}

In vivo, CS exposure increased focal emphysema as well as IL-8 and LTB4 levels (Figure 4) in the BAL fluid compared to the sham group. Treatment with ROSI decreased the secrections of IL- 8 and LTB4 induced by CS, and co-treatment with BADGE weakened above effects of ROSI on cytokines (LTB4 and IL-8).

In vitro test, similar to the results in vivo, 5\% CSE exposure increased significantly the IL- 8 and LTB4 secretions by AMs. ROSI and 15d-PGJ2 attenuated the CSE-induced releases of LTB4 and IL-8 (Figure 5).
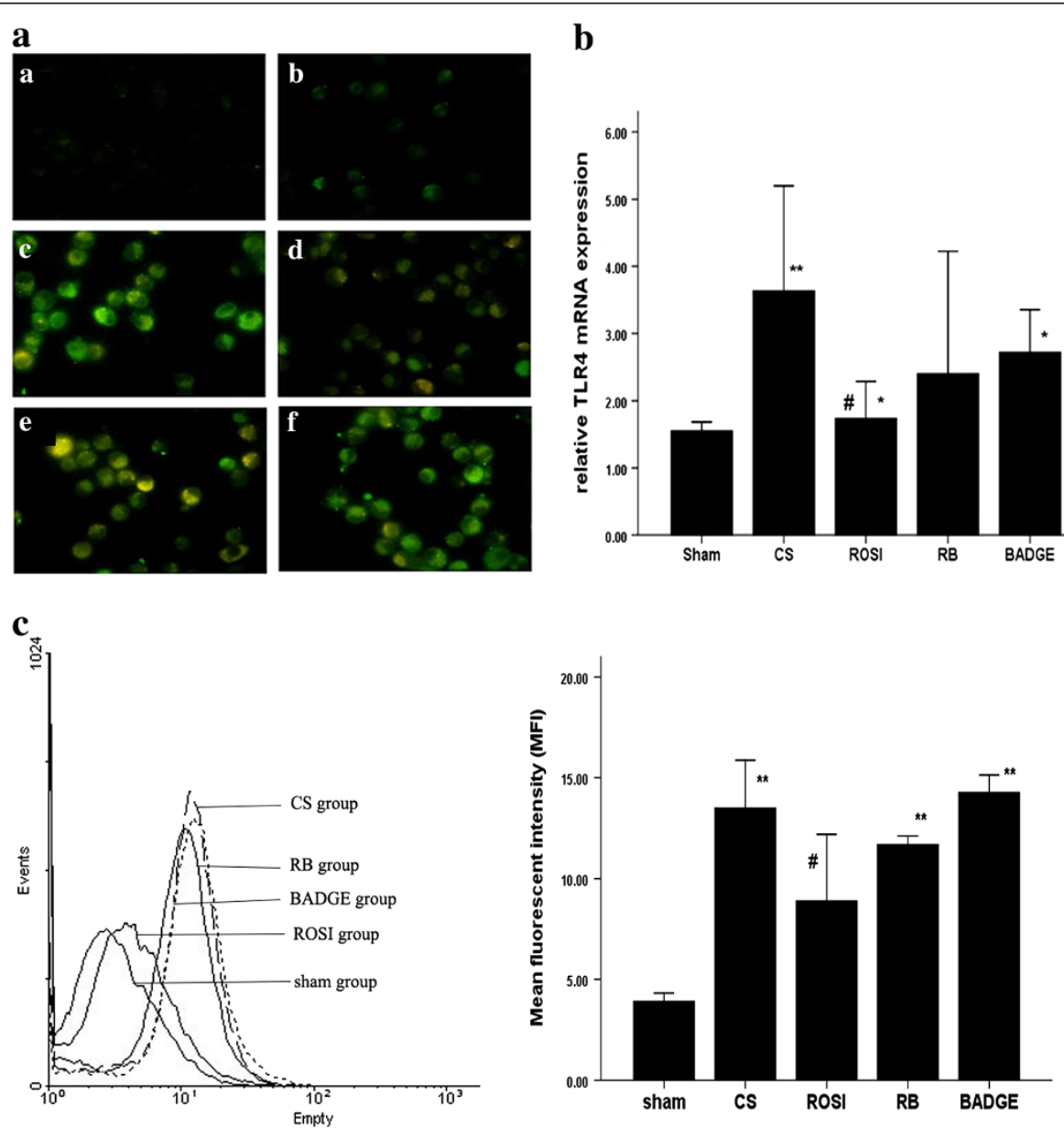

Figure 6 Expression of TLR4 in AMs gained from each group. a: Immunofluorescence of AMs from each group of rats with antibodies to TLR4 (green). Representative TLR4 expression was shown in the negative control group (a), the sham (b), CS (c), ROSI (d), RB (e) groups and BADGE ( $f$. Shown are representative images of five rats in each group; $\mathbf{b}$ : mRNA expression of TLR4 in AMs. The data are representative of six rats in each group. c: representative flow cytometry histogram showing surface protein expression of TLR4 in AMs. The data are representative of six rats in each group. The results are presented as mean \pm SD. ${ }^{*} P<0.05$ and ${ }^{* *} P<0.01$ compared with the sham group; $\# P<0.05$ and $\# \# P<0.01$ compared with the CS group. 


\section{Involvement of TLR4 in CS-induced inflammatory cytokine production}

We investigated whether TLR4 were involved in CSinduced increases of inflammatory cytokines. We found that CS exposure increased TLR4 expression (Figures 6, 7, 8 and 9) as well as IL-8 and LTB4 levels in vivo and in vitro. And pretreatment with neutralizing TLR4 antibody (10 ug/ml) deduced the releases of IL-8 and LTB4 induced by $5 \%$ CSE (Figure 10). The effect of neutralizing TLR4 antibody on cytokines was similar to that of 15d-PGJ2 or ROSI. Compared to treatment with 15d-PGJ2 or ROSI alone, there was a trend toward a reduction of LTB4 $(695.6 \pm 52.84$ vs $671.1 \pm 162.22,802.4 \pm 88.76$ vs $754.9 \pm 101.27)$ and IL-8 $(296.7 \pm 30.38$ vs $294.9 \pm 43.30, \quad 303.4 \pm 38.68$ vs $269.6 \pm$ 59.10 ) in presence of neutralizing TLR4 antibody, but none of differences were statistical significance.

\section{PPAR $\gamma$ ligands attenuated the expression of TLR4 at} message and protein levels as well as cell surface level in AMs

We found that CS downregulated PPAR $\gamma$ expression while upregulated TLR2 and TLR4 expression in AMs in vivo. Compared to CS exposure, treatment with ROSI increased the expressions of PPAR $\gamma$, but decreased the expression of TLR2 and TLR4 in vivo (Figures 6, 11 and 12). Similar to the in vivo study, $5 \%$ and $10 \%$ CSE decreased mRNA and protein expressions of PPAR $\gamma$, while increased mRNA, protein expressions and surface levels of TLR4 in vitro (Figures 7 and 8). Pretreatment with either ROSI or 15d-PGJ2 attenuated the mRNA and surface levels of TLR4 (but not TLR2) induced by 5\% CSE (Figure 9 and Additional file 1: Figure S4), and

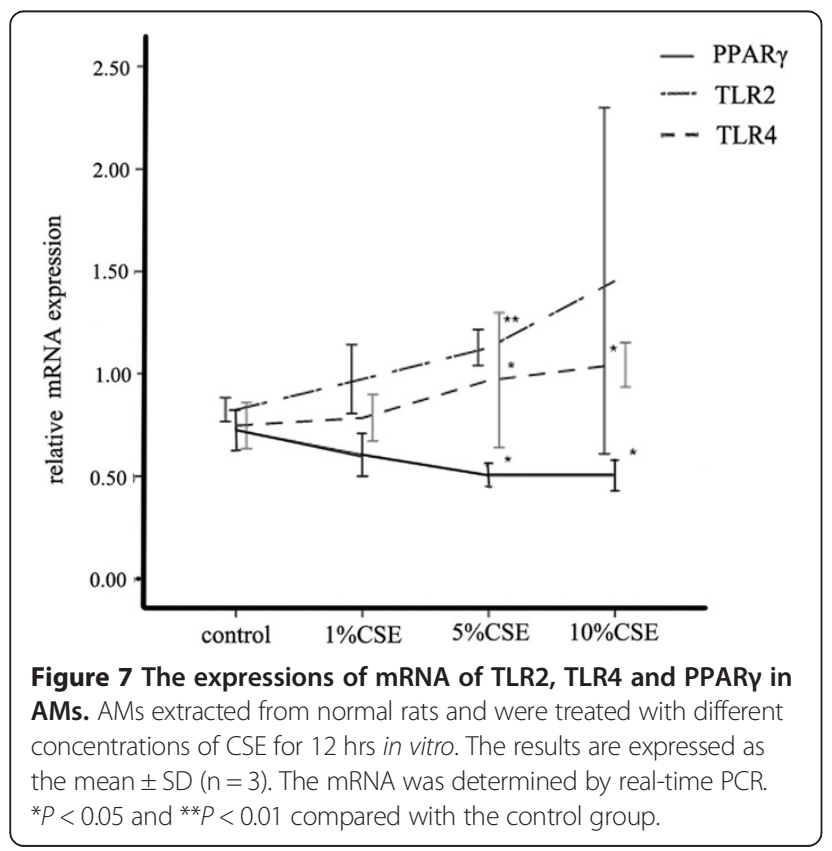

the effects of the PPAR $\gamma$ agonists were blocked by treatment with BADGE in vitro.

We next investigated whether NF- $\mathrm{B}$ bere involved in PPAR $\gamma$ mediated inhibition of TLR4. CS enhanced I $\mathrm{KB} \alpha$ degradation and increased P65, TLR4 in AMs in vivo and in vitro. And pretreatment with PPARy ligands (ROSI or

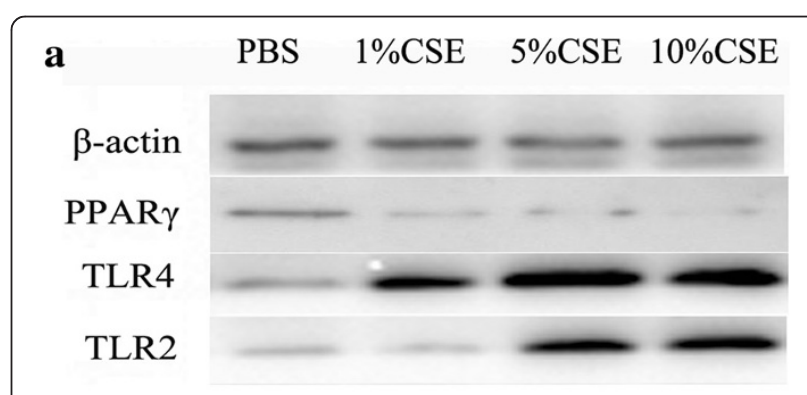

b

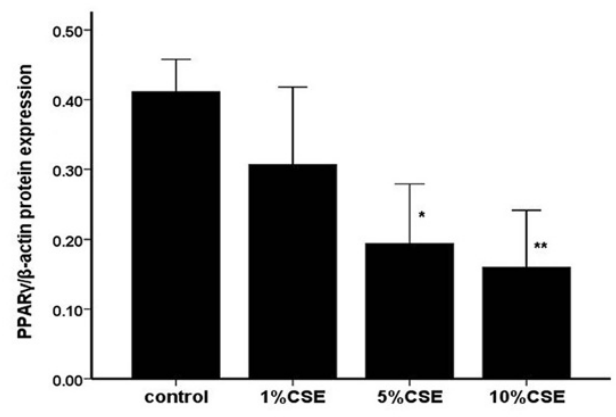

c

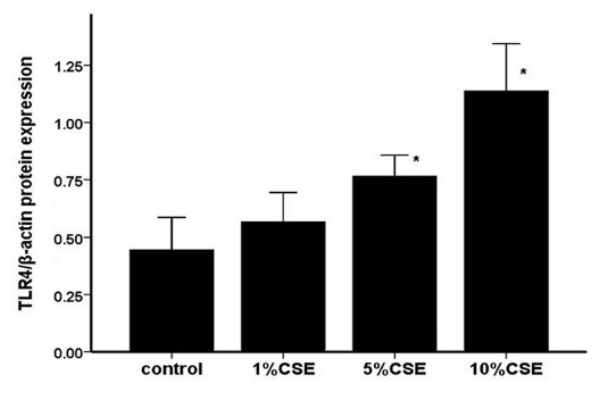

d

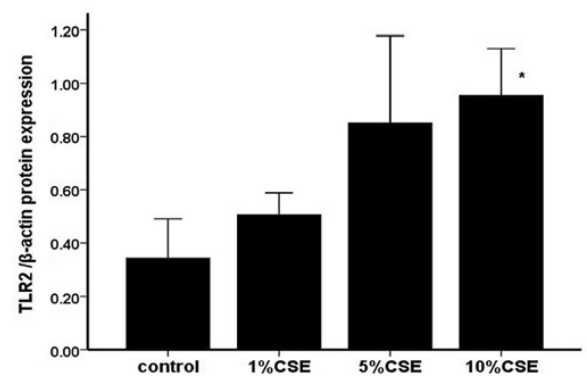

Figure 8 The protein expressions of TLR2, TLR4 and PPARY in AMs. AMs extracted from normal rats and were treated with different concentrations of CSE for 12 hrs in vitro. The protein expression was determined by western blotting. a: Representative Western blot of TLR2, TLR4, PPARY and actin. Image analysis of PPARY (b), TLR4 (c) and TLR2 (d) determined by densitometry. The results are expressed as the mean $\pm S D(n=3)$. ${ }^{*} P<0.05$ and ${ }^{* *} P<0.01$ compared with the control group. 

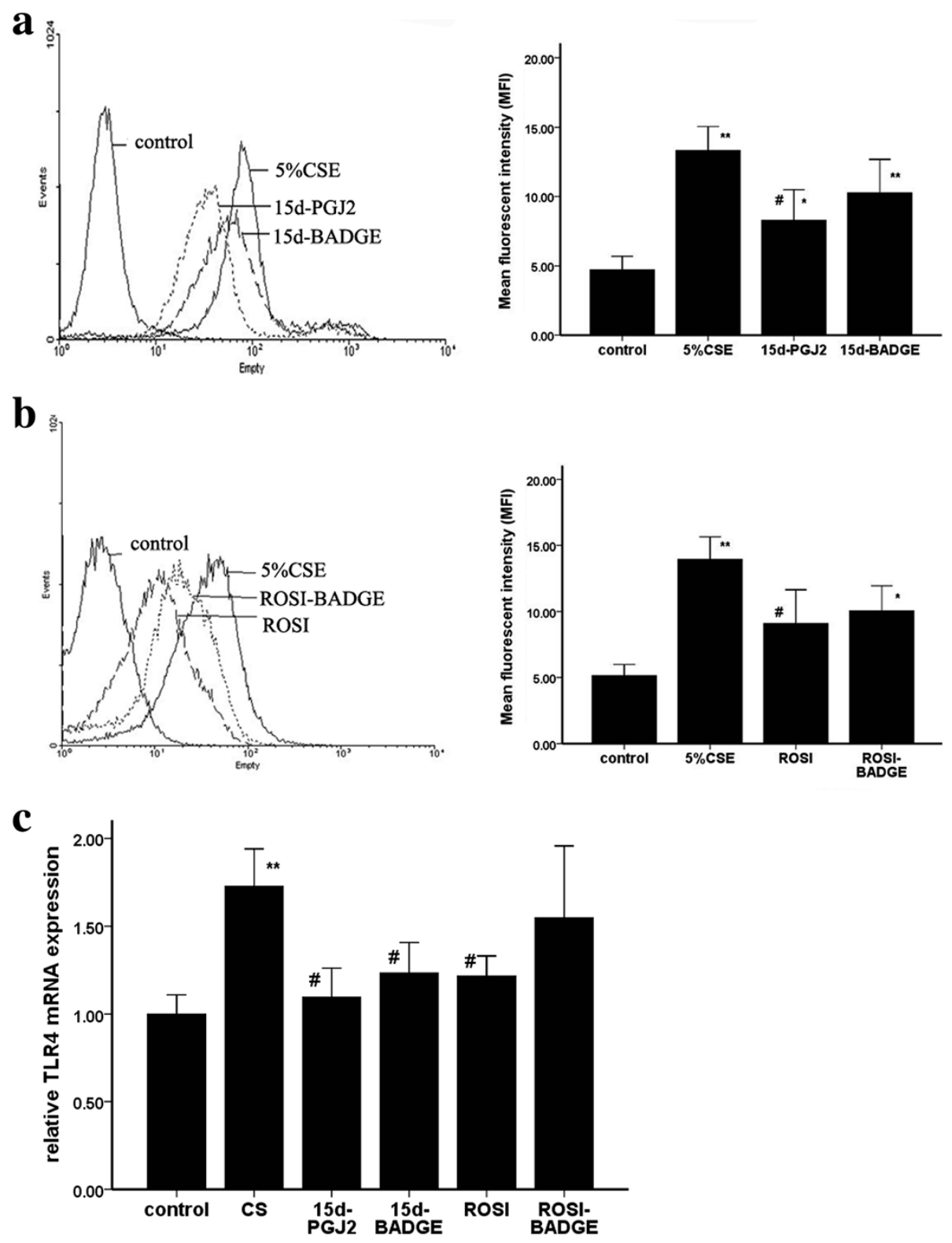

Figure 9 The effect of $\mathbf{5 \%}$ CSE on TLR4 expression in vitro. The results are expressed as the mean \pm SD $(n=4)$. $\mathbf{a}$ and $\mathbf{b}$ : representative flow cytometry histogram showing TLR4 expression on AMs treated with 5\% CSE for 12 hrs. Representative flow cytometry histogram showing TLR4 expression on AMs. c: the expressions of mRNA of TLR4 in AMs. The mRNA was determined by real-time PCR. ${ }^{*} P<0.05$ and ${ }^{* *} P<0.01$ compared with the CSE-exposed group.

15d-PGJ2) decreased IкB $\alpha$ degradation, and inhibited TLR4 expressions induced by CS (Figures 13 and 14). We also found that NF- $\mathrm{kB}$ inhibitor PDTC reversed the increases of TLR4 induced by $5 \%$ CSE (Figure 15).

\section{Discussion}

Cigarette smoking is a major factor influencing ongoing inflammation in the airways and lung parenchyma, with the severity of airflow limitation being correlated with the degree of pulmonary inflammation. Cigarette smoke causes airway inflammation by activating macrophages, neutrophils, and $\mathrm{T}$ lymphocytes. As the first line of defense against inhaled constituents, AMs are directly involved in the secretion of cytokines, including IL-8 and LTB4, and the degradation of the extracellular matrix, and can enhance emphysema [18-20]. AMs are thought to be the main orchestrators of the chronic inflammatory response and tissue destruction observed in COPD patients [21]. Similarly, our studies observed that exposure to cigarette smoke induced emphysema (data shown in the Additional file 1), while increased the total cells number counts and number of AMs in BAL fluid, 


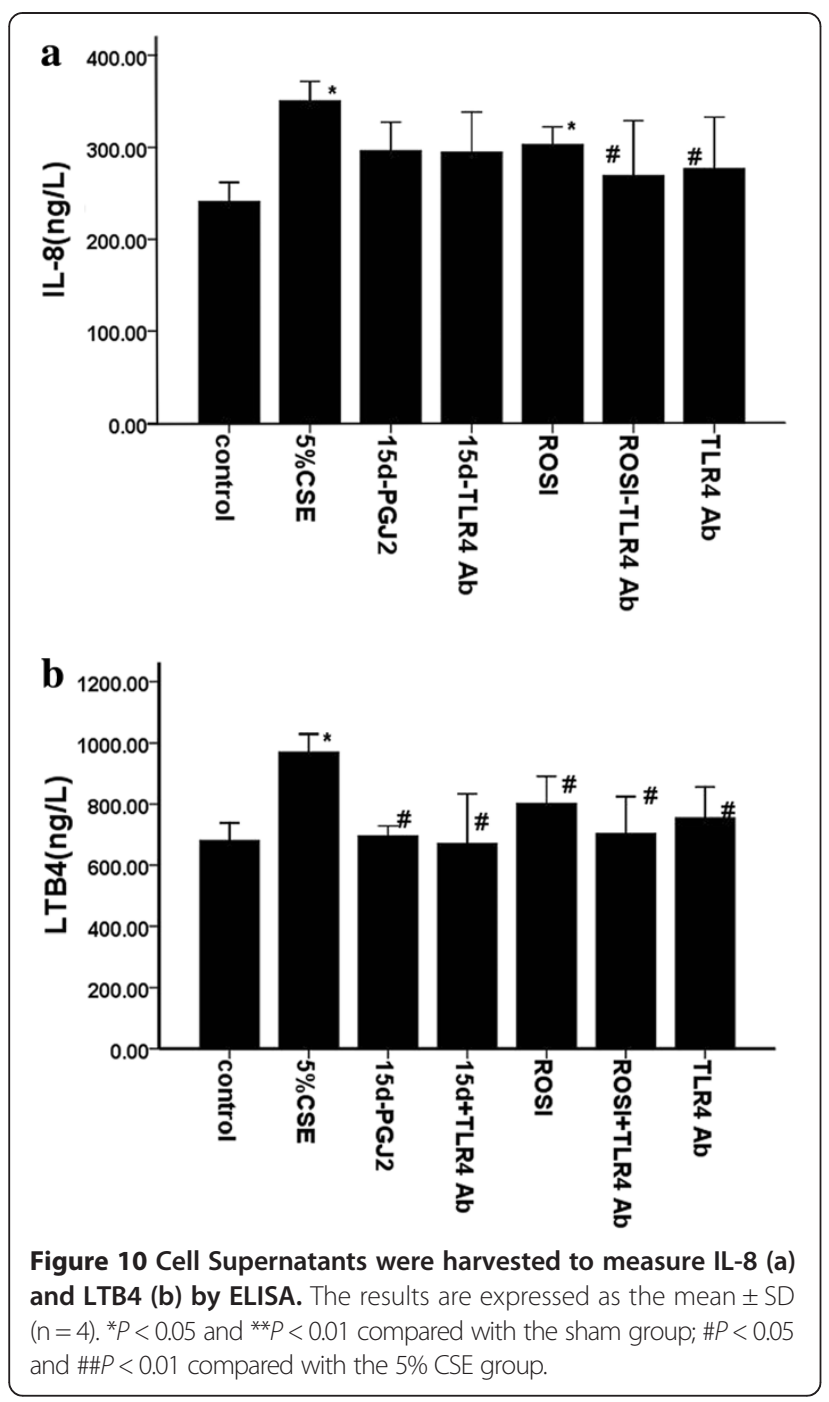

decreased AMs phagocytosis and AMs viability, and increased IL-8 and LTB4 releases by AMs in vivo and in vitro. Thus, AMs were thought to be a main component of the inflammatory response to cigarette smoke.

The nuclear hormone receptor PPARY plays an important role in a diverse range of biological processes, including the prevention of acute inflammation. Peroxisome proliferator-activated receptors (PPARs) exert antiinflammatory effects in several cell types, such as smooth muscle cells, endothelial cells, and macrophages. Several studies have demonstrated that the in vivo administration of PPAR $\gamma$ ligands inhibited adjuvantinduced arthritis, colitis, and atherosclerosis in animal models [22-24], raising the possibility that PPAR $\gamma$ might be a critical component of the inflammatory process. Strong expression of PPAR $\gamma$ was seen in freshly isolated human AMs. It had been shown in mouse and human that PPARy deletion from AMs was associated with resolution of inflammation and airway immunity [25], and PPAR- $\gamma$ ligands upregulated phagocytosis of AMs $[26,27]$. The findings above suggested that it may be an protective function of PPAR- $\gamma$ agonists in promoting inflammation resolution in AMs.

Some researchs showed that PPAR $\gamma$ expression levels was reduced in lungs of patients with moderate and severe COPD [28], in macrophages gained from BALF of COPD patients when stimulated with IFN- $\gamma$ [29], and in the skeletal muscle of COPD patients [30], whereas it was increased in the lungs of rats which treated with CS + Lipopolysaccharides (LPS) and patients with mild COPD. Conversely, proportion of macrophages staining for PPAR$\gamma$ protein in tissue was similar in COPD patients [26]. In the present study, we investigated biological actions of PPAR- $\gamma$ on cigarette smoke induced pulmonary inflammation in AMs. We observed that CS decreased PPAR $\gamma$ expression in AMs in vivo and in vitro. Here, we also found that the administration of PPAR $\gamma$ ligands (ROSI or 15dPGJ2) attenuated the CS-induced inflammation in AMs in vivo and in vitro: compared to CS-treatment, the decreases in pro-inflammatory cytokines, the reductions in obvious morphological changes caused by increases in an emphysema-like phenotype and totol cell number in BAL fluid, and the increases in the phagocytosis and viability of AMs. Our findings demonstrated that PPAR $\gamma$ had antiinflammatory effects on CS-induced inflammation, and it might be participated in the pathogenesis of COPD.

TLR-mediated signaling might play a crucial role in CDinduced inflammatory production [31-33]. In addition, some report suggested that TLR2 and TLR4 genes are associated with (changes in) numbers of inflammatory cells as well as with decline of lung function [34]. Our results showed that the surface protein expression of TLR4, but not of TLR2, was increased in AMs as a response to CS, accompanied with increased inflammatory cytokins secretion in vivo and in vitro, confirming the results of several reports that have demonstrated changes in the expression of TLR4 in the epithelial cells and monocytes of COPD patients [35-37]. In the present study, we used neutralizing antibody for TLR4 to investigate the role of TLR4 in CS-induced inflammation in AMs. We found that CS upregulated both TLR4 expression and IL-8 and LTB4 releases in a dose-dependent manner. And neutralizing TLR4 antibody partially suppressed the inflammatory cytokines induced by $5 \%$ CSE. These observations indicated that TLR4-mediated inflammatory signal was implicated in the CS-related inflammatory pathogenesis.

The precise mechanism by which PPARy exerts antiinflammatory effects in AMs is poorly understood. We explored the PPAR $\gamma$ signaling pathway and searched for a relationship with the TLR4 signaling pathway in vivo and in vitro. Therefore, we further investigated the effects of two different PPARY ligands, 15d-PGJ2 and 
a
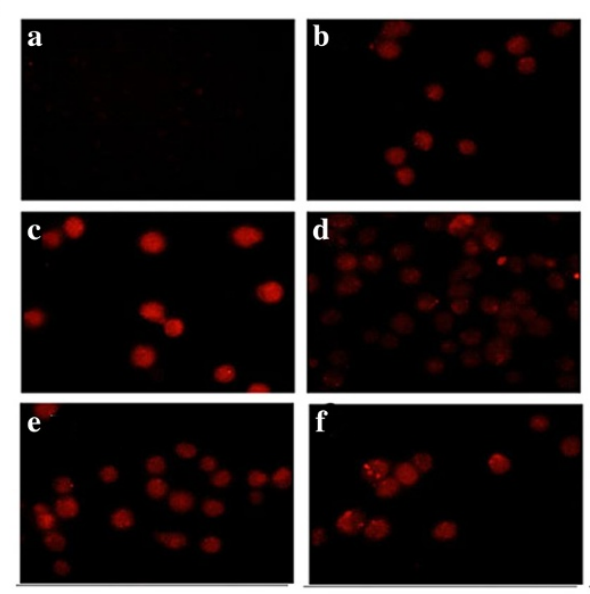

d

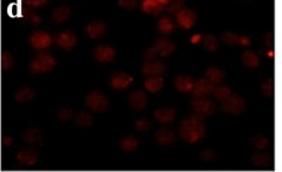

b

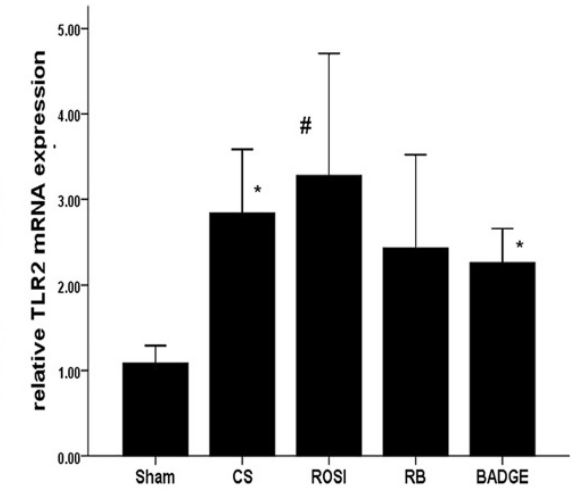

c
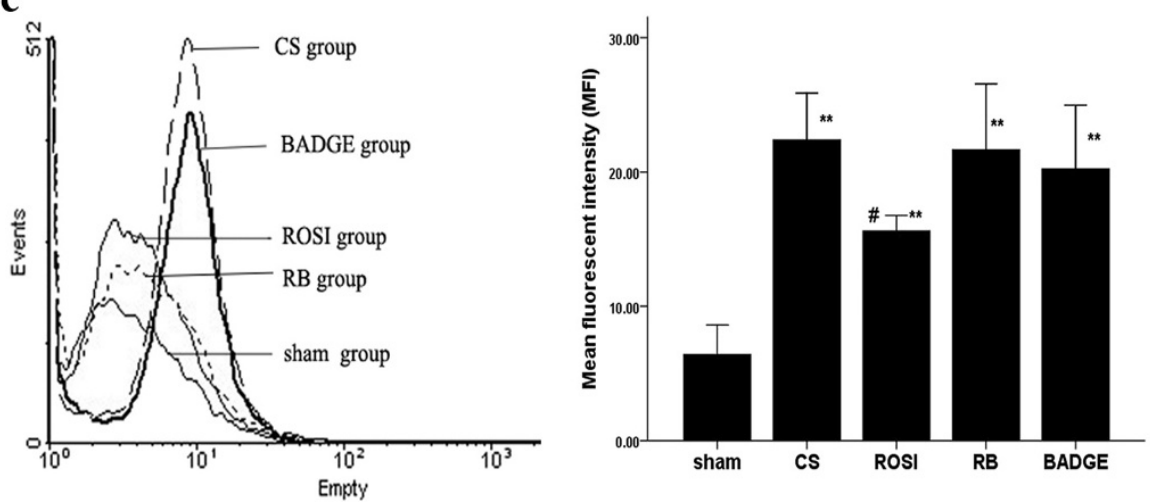

Figure 11 Expression of TLR2 in AMs gained from each group. a: Immunofluorescence of AMs from each group of rats with antibodies to TLR2 (red). Representative TLR2 expression was shown in the negative control group (a), the sham (b), CS (c), ROSI (d), RB (e) groups and BADGE (f). Shown are representative images of five rats in each group; $\mathbf{b}$ : mRNA expression of TLR2 in AMs. The data are representative of six rats in each group. c: representative flow cytometry histogram showing surface protein expression of TLR2 in AMs. The data are representative of six rats in each group. The results are presented as mean \pm SD. ${ }^{*} P<0.05$ and ${ }^{* *} P<0.01$ compared with the sham group; \#P<0.05 and \#\#P<0.01 compared with the CS group.

ROSI, on the expression of TLR4 in vitro. We found that treatment with the PPARY ligands reversed the CSinduced increase in TLR4 expression, confirming the results of other studies that investigated colon epithelial cells [38]. In this study, the effects of PPARY ligands on TLR4 and cytokines secretions could be partially attenuated by treatment with PPAR $\gamma$ antagonist (BADGE). These data suggested that the effects of 15d-PGJ2 and ROSI on the upregulations of TLR4, IL- 8 and LTB4 induced by CS were partially PPAR $\gamma$-dependent. Modulation of IL- 8 and LTB4 production of PPAR $y$ ligands was also studied in the presence of TLR4 inhibitor. Our data showed that neutralizing TLR4 antibody significant inhibited the cytokin production, but could not enhance the effects of PPARY ligands on cytokine release. We speculated the reasons of this phenomenon as followed: The finite effect of CSE on TLR4 expression might induce ceiling phenomenon. Thus the effect of PPAR $\gamma$ ligands on TLR4 did not stack with other TLR4 inhibitor increasing effects. The founding provided additional evidence for the role of the PPAR $\gamma$-TLR4 pathway in inflammation.

Previous research has indicated that CS induces the release of pro-inflammatory cytokines in the monocytemacrophage MonoMac6 cell line by activating NF- $\mathrm{KB}$ [21], and NF- $\mathrm{KB}$ plays a crucial role in regulating many proinflammatory mediators, including TLR4 [39]. We investigated the expression of TLR4 in the presence or absence of the NF-kB inhibitor PDTC in vitro. We found that PDTC could significantly reduce TLR4 protein expression induced by CS, possibly via some direct inhibitory effect of blockage of NF-kB on TLR4 expression. Thus, the inhibition of NF-kB by PDTC verified the importance of the NF-kB-TLR4 pathway in CS-induced inflammation. PPAR $\gamma$ have been shown to interact directly with intracellular proteins and regulate signaling pathway through modifying protein function, including the inhibition of IkB $\alpha$ degradation and the reduction of RelA (p65) 


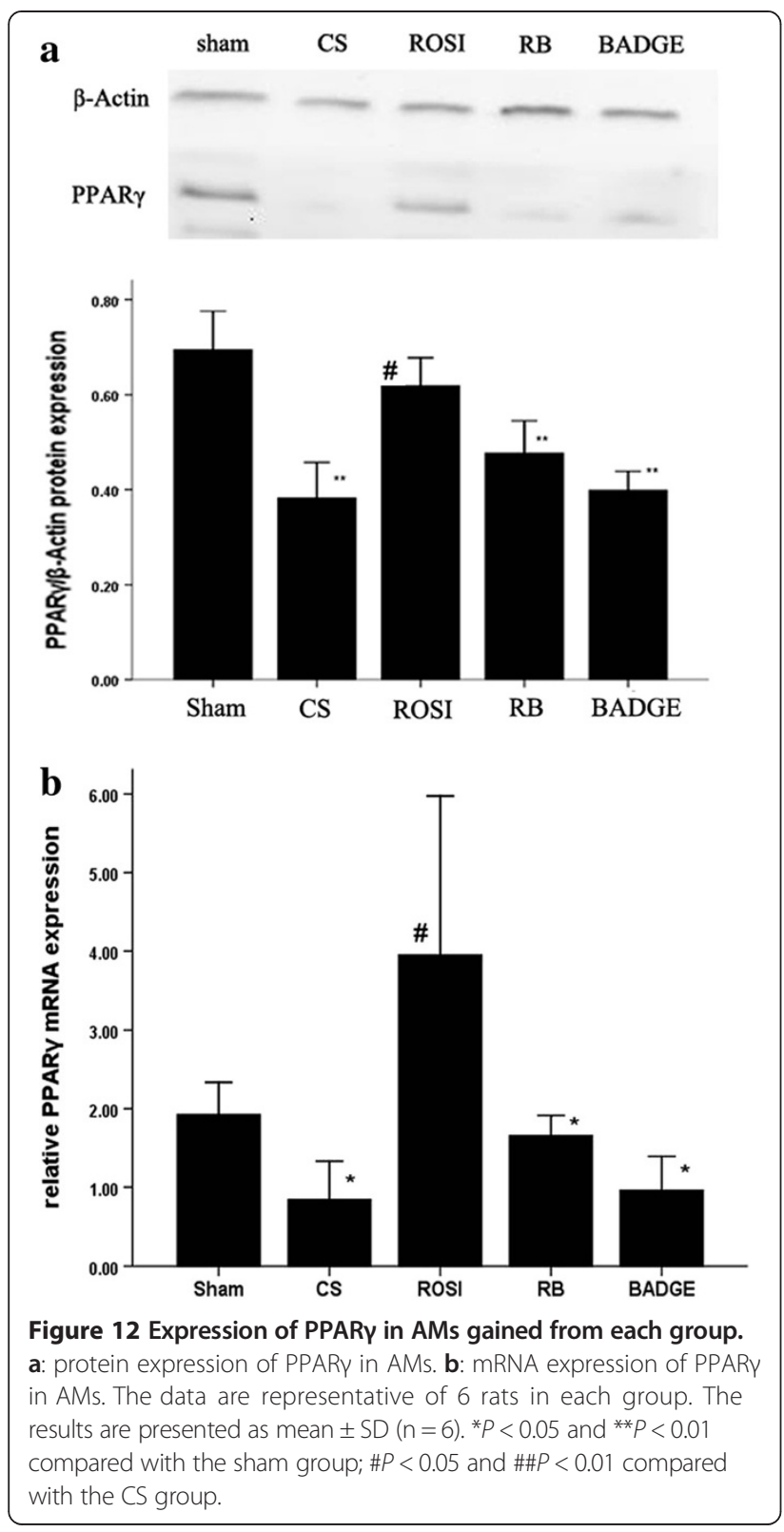

nuclear translocation. The current in vitro experiment showed that both 15d-PGJ2 and ROSI treatment delayed CS-induced I $\mathrm{K} \mathrm{B} \alpha$ degradation and increased P65 expression in AMs. Based on these reports and our study, it was possible that PPARy ligands (15d-PGJ2 and ROSI) may associate with certain signaling molecules (NF- $\mathrm{kB})$ in the TLR4 signaling pathway. However, the exact mechanism need further study.

Some of the limitations of our study should be acknowledged. First, the study utilized AMs from Wistar rats. It is not known whether the same results can be observed in human cells, but these findings suggest that animal model therapeutic trials for smoke-induced lesions might better
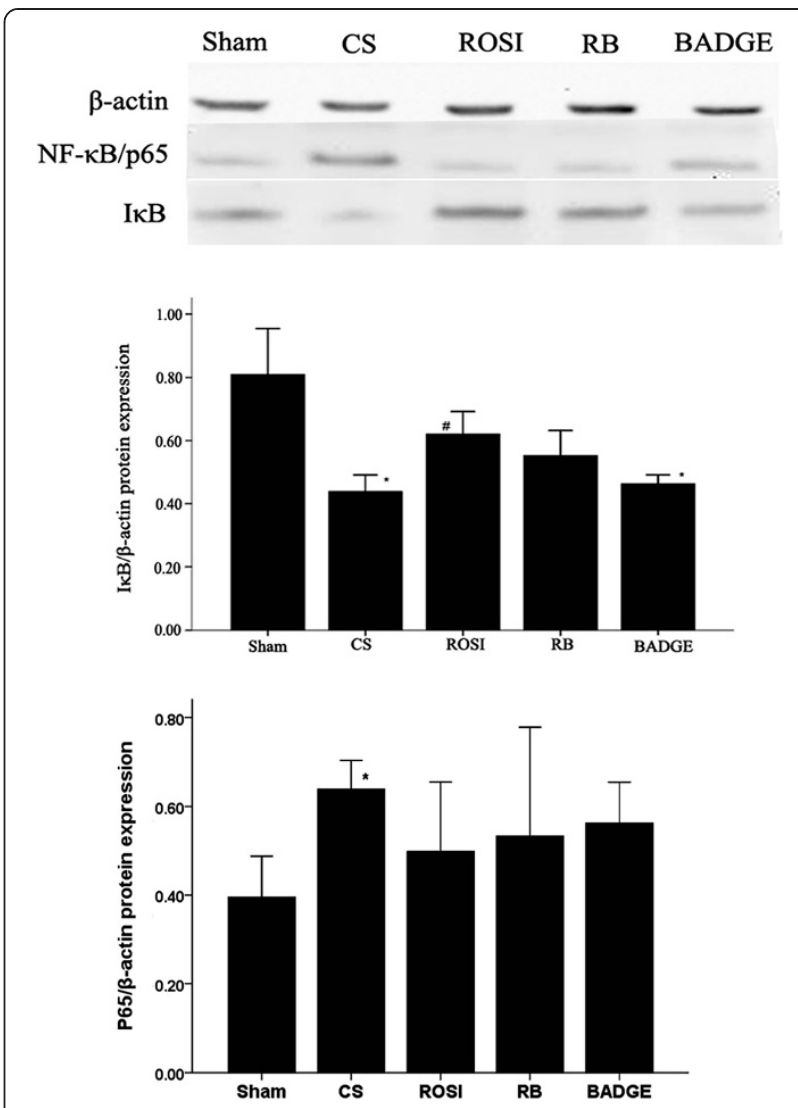

Figure 13 Western blot analysis of IKBa degradation and P65 expression in AMs. The data are representative of 6 rats in each group. The cells were harvested from each group. Four more experiments gave similar results. ${ }^{*} P<0.05$ and ${ }^{*} P<0.01$ compared with the sham group. $\# P<0.05, \# \#<<0.01$, compared with the CS group.

predict which drugs will be effective in treating COPD if the trials include an intervention arm that starts well into the exposure period. In addition, AMs are the only cells in the myeloid lineage that contain liver-type fatty acid binding protein (L-FABP) [40]. L-FABP is necessary for the nuclear signaling of PPAR $\gamma$ [41]. A previous study has shown that AMs constitutively express high levels of PPAR- $\gamma$. Therefore, we investigated the function of PPAR $\gamma$ in AMs. AMs are known to vary from other cells, including PMs, making it difficult to ascertain whether the protective role of PPARy is limited to AMs or not. Second, our study emphasized the expression of only one PPAR subtype, despite the anti-inflammatory effect of the other subtypes. Third, We used rosiglitazone at the lower doses that are effective in animal models [42-44]. Although, a previous study found that only higher doses of the PPAR ligands could affect viability and systemic side effects. Our study will further investigate the relationship between the dose of the PPAR $\gamma$ ligands and the side effects; Finally, inflammation 


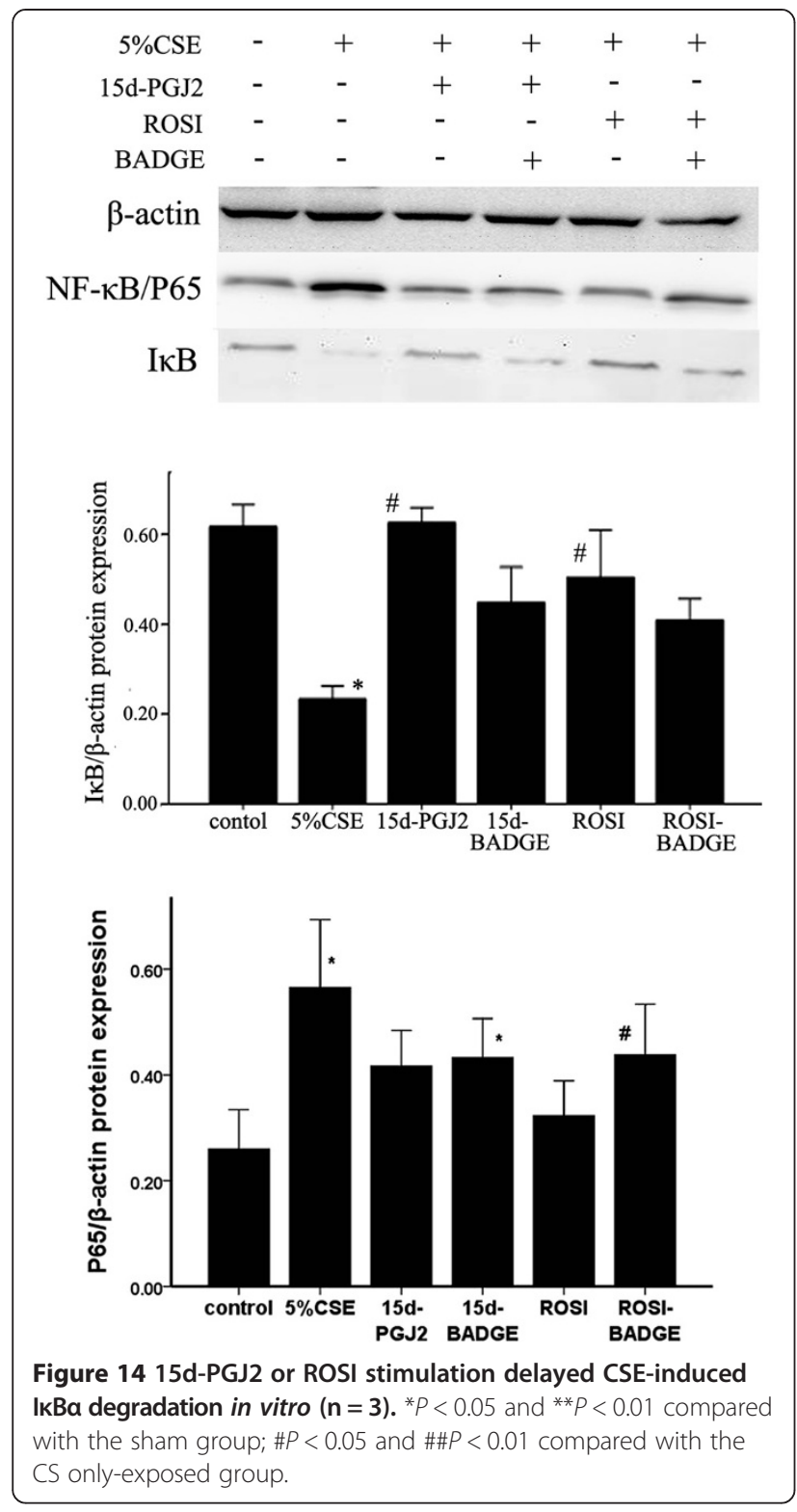

is a complicated, interconnected network, and our study only investigated IL-8 and LTB4 from a vast array of other cytokines.

\section{Conclusions}

We proved that PPARY ligands inhibits CS-induced inflammation through a PPAR $\gamma$-dependent mechanism that functions downstream of TLR4 and activates NF$\mathrm{kb}$ transcriptional activity. Further investigation into the mechanisms by which PPAR $\gamma$ regulates AM function will improve our understanding of the role of PPARY in chronic airway inflammation.
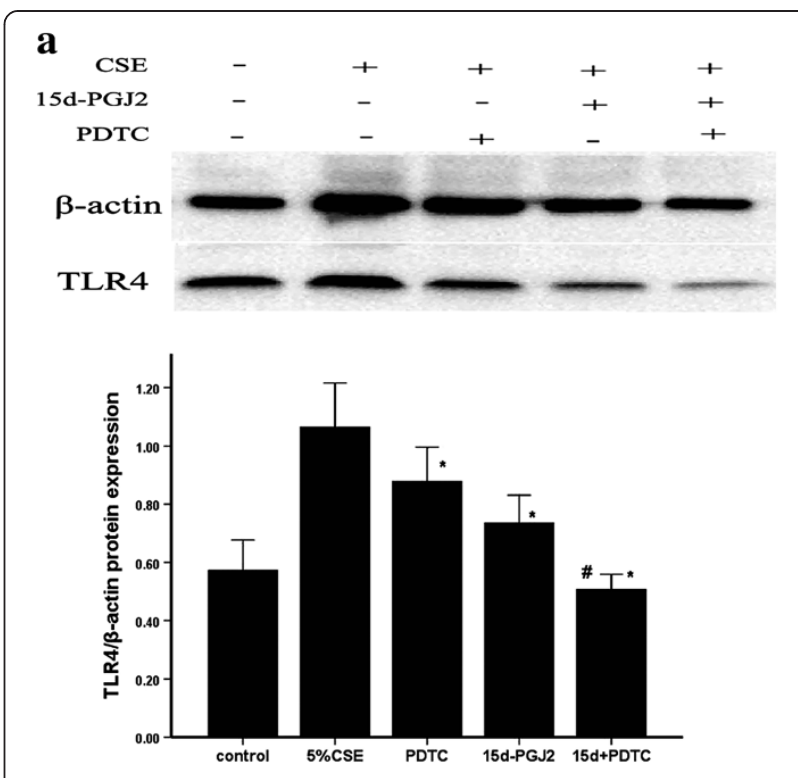

b
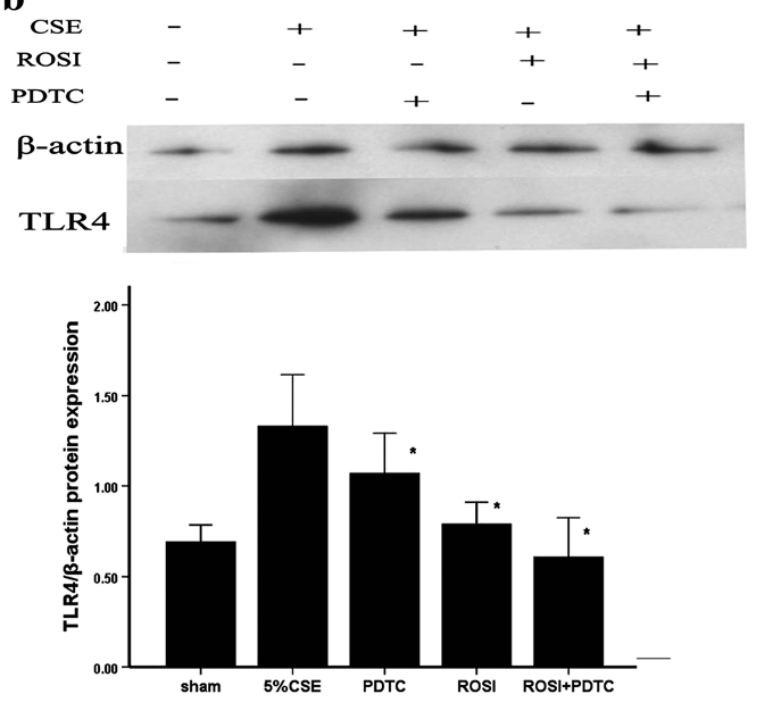

Figure 15 The effect of PDTC on the PPARY-mediated inhibition of TLR4 in vitro $(\mathbf{n}=\mathbf{3})$. a The AMs in response to $15 \mathrm{~d}-\mathrm{PGJ} 2$ and PDTC pretreatment interventions. $\mathbf{b}$ The AMs in response to ROSI and PDTC pretreatment interventions. ${ }^{*} P<0.05$ and ${ }^{* *} P<0.01$ compared with the CS only-exposed group; \#P $<0.05$ and \#\#P $<0.01$ compared with the PPARY ligands (15d-PGJ2 and ROSI) group.

\section{Additional file}

Additional file 1: Figure S1. Prime-boost protocols for the animal experiments. Male Wistar rats were randomized into five groups of 12 animals each: sham; cigarette smoking (CS) only-exposed; rosiglitazone (ROSI)-treated; BADGE-treated; and RB-treated. The rats were sacrificed 1 week after the last smoke exposure. Figure S2. Photomicrographs of HE-stained lung tissue from sham (a), CS only-exposed (b), ROSI-treated (c), BADGE-treated (d), and RB-treated (e). HE staining; original magnification $\times 100$. Figure S3. Photomicrographs of HE-stained lung tissue from sham (a), 
CS only-exposed (b), ROSI-treated (c), BADGE-treated (d), and RB-treated (e). HE staining; original magnification $\times 400$. Figure S4. The effect of 5\% CSE on TLR2 expression in vitro. The results are expressed as the mean \pm SD $(n=4)$. Figure 10a and Figure 10b: representative flow cytometry histogram showing TLR2 expression on AMs treated with 5\% CSE for 12 hrs. Representative flow cytometry histogram showing TLR2 expression on AMs. Figure 10c: the expressions of mRNA of TLR2 in AMs. The mRNA was determined by real-time $P C R$. ${ }^{*} P<0.05$ and ${ }^{*}{ }^{*} P<0.01$ compared with the CSE-exposed group. Table S1. Morphometric results (mean linear intercept [MLI] and mean alveolar numbers [MAN]) in different groups. Table S2. Pulmonary function in CS group and Sham group.

\section{Abbreviations}

COPD: Chronic obstructive pulmonary disease; TLR: Toll like receptor; PPAR: Peroxisome proliferator-activated receptors; BALF: Bronchoalveolar lavage; ELISA: Enzyme-linked immunosorbent assay; LTB4: Leukotriene B4; IL-8: Interleukin-8; RT-PCR: Reverse transcription-polymerase chain reaction; CSE: Cigarette smoke extrat; AMs: Alveolar macrophage; MTT: 3-(4,5Dimethylthiazol-2-yl)-2,5-diphenyltetrazolium bromide; NF-KB: Nuclear factor kappa B; 15d-PGJ2: 15-deoxy-Delta12,14- prostaglandin J2; BADGE: Bisphenol A diglycide ether.

\section{Competing interests}

The authors declare that they have no competing interests.

\section{Authors' contributions}

YY conducted the experiments and wrote the manuscript, GH and EL contributed to the molecular biological experiments and QW and JK contributed to the design and finance of the experiments. All authors read and approved the final manuscript.

\section{Acknowledgements}

All authors participated in the design and interpretation of the studies, analysis of the data and review of the manuscript.

\section{Funding}

(i) Major science research project of medicine summit construction supported by the Health Department of Liaoning Province, PRC, Project Number 200907; (ii) Clinical Study on Translational Medicine of Respiratory Disease supported by The National Key Technology R\&D Program of the 12th National Five-year Development Plan, Project Number 2012BAI05B01.

Received: 14 May 2013 Accepted: 19 February 2014

Published: 11 March 2014

\section{References}

1. Rahman I, MacNee W: Lung glutathione and oxidative stress: implications in cigarette smoke-induced airway disease. Am J Physiol 1999, 277(6 Pt 1):L1067-L1088.

2. Zhu Y, Kan L, Qi C, Kanwar YS, Yeldandi AV, Rao MS, Reddy JK: Isolation and characterization of peroxisome proliferator-activated receptor (PPAR) interacting protein (PRIP) as a coactivator for PPAR. J Biol Chem 2000, 275(18):13510-13516.

3. Caito S, Yang SR, Kode A, Edirisinghe I, Rajendrasozhan S, Phipps RP, Rahman I: Rosiglitazone and 15-deoxy-Delta12, 14-prostaglandin J2, PPARgamma agonists, differentially regulate cigarette smoke-mediated pro-inflammatory cytokine release in monocytes/macrophages. Antioxid Redox Signal 2008, 10(2):253-260.

4. Jahoor A, Patel R, Bryan A, Do C, Krier J, Watters C, Wahli W, Li G, Williams SC, Rumbaugh KP: Peroxisome proliferator-activated receptors mediate host cell proinflammatory responses to Pseudomonas aeruginosa autoinducer. J Bacteriol 2008, 190(13):4408-4415.

5. Okada M, Yan SF, Pinsky DJ: Peroxisome Proliferator-activated receptor activation suppresses isehemic induction of Egr-1 and its inflammatory gene targets. FASEB J 2002, 16:1861-1868.

6. Woerly G, Honda K, Loyens M, Papin JP, Auwerx J, Staels B, Capron M, Dombrowicz D: Peroxisome proliferator-activated receptor and downregulate allergic inflammation and eosinophil activation. J Exp Med 2003, 198(3):411-421.
7. Benayoun L, Letuve S, Druilhe A, Boczkowski J, Dombret MC, Mechighel P, Megret J, Leseche G, Aubier M, Pretolani M: Regulation of peroxisome proliferator-activated receptor expression in human asthmatic airways. Am J Respir Crit Care Med 2001, 164(8 Pt 1):1487-1494.

8. Kliewer SA, Forman BM, Blumberg B, Ong ES, Borgmeyer U, Mangelsdorf DJ, Umesono K, Evans RM: Differential expression and activation of a family of murine PPARs. Proc Natl Acad Sci USA 1994, 91(15):7355-7359.

9. Eun CS, Han DS, Lee SH, Paik CH, Chung YW, Lee J, Hahm JS: Attenuation of colonic inflammation by PPAR gamma in intestinal epithelial cells: effect on Toll-like receptor pathway. Dig Dis Sci 2006, 51(4):693-697.

10. Nencioni A, Wesselborg S, Brossart P: Role of peroxisome proliferatoractivated receptor gamma and its ligands in the control of immune responses. Crit Rev Immunol 2003, 23(1-2):1213-1219.

11. Di Stefano A, Capelli A, Lusuardi M, Balbo P, Vecchio C, Maestrelli P, Mapp CE, Fabbri LM, Donner CF, Saetta M: Severity of airflow limitation is associated with severity of airway inflammation in smokers. Am J Respir Crit Care Med 1998, 158(04):1277-1285.

12. Finkelstein R, Fraser RS, Ghezzo H, Cosio MG: Alveolar inflammation and its relationship to emphysema in smokers. Am J Respir Crit Care Med 1995, 152(5pt1):1666-1672.

13. Fernandez S, Jose P, Avdiushko MG, Kaplan AM, Cohen DA: Inhibition of IL10 receptor function in alveolar macrophages by Toll-like receptor agonists. J Immunol 2004, 172(4):2613-2620.

14. Castoldi A, Braga TT, Correa-Costa M, Aguiar CF, Bassi EJ, Correa-Silva R, Elias RM, Salvador F, Moraes-Vieira PM, Cenedeze MA, Reis MA, Hiyane ML, Pacheco-Silva A, Gonçalves GM, Olsen N, Câmara S: TLR2, TLR4 and the MYD88 Signaling Pathway Are Crucial for Neutrophil Migration in Acute Kidney Injury Induced by Sepsis. PloS one 2012, 7(5):e37584.

15. Donnelly LE, Tudhope SJ, Fenwick PS, Barnes PJ: Effects of formoterol and salmeterol on cytokine release from monocyte-derived macrophages. Eur Respir J 2010, 36:178-186.

16. Weeks BA, Keisler AS, Myrvik QN, Warinner JE: Differential uptake of neutral red by macrophages from three species of estuarine fish. Dev Comparat Immunol 1987, 11:117-124.

17. Livak KJ, Schmittgen TD: Analysis of relative gene expression data using real-time quantitative PCR and the $2 \Delta \Delta \mathrm{Ct}$ method. Methods 2001, 25:402-408.

18. Martin TR, Frevert CW: Innate immunity in the lungs. Proc Am Thorac Soc 2005, 2(5):403-411.

19. Keatings VM, Collins PD, Scott DM, Barnes PJ: Difference sininter leukin-8 and tumor necrosis factor-alpha in induced sputum from patients with chronic obstructive pulmonary disease or asthma. Am J Respir Crit Care Med 1996, 153(2):530-534.

20. Hill AT, Bayley D, Stockley RA: The interrelationship of sputum inflammatory markers in patients with chronic bronchitis. Am J Respir Crit Care Med 1999, 160(3):893-898.

21. Di Stefano A, Capelli A, Lusuardi M, Balbo P, Vecchio C, Maestrelli P, Mapp $C E$, Fabbri LM, Donner CF, Saetta M: Severity of airflow limitation is associated with severity of airway inflammation in smokers. Am J Respir Crit Care Med 1998, 158:1277-1285.

22. Su CG, Wen X, Bailey ST, Jiang W, Rangwala SM, Keilbaugh SA, Flanigan A, Murthy S, Lazar MA, Wu GD: A novel therapy forcolitis utilizing PPAR ligands to inhibit the epithelial inflammatory response. J Clin Invest 1999, 104:383.

23. Jackson SM, Parhami F, Xi XP, Berliner JA, Hsueh WA, Law RE, Demer LL: Peroxisome proliferator-activated receptor activators target human endothelial cells to inhibit leukocyte-endothelial cell interaction. Arterioscler Thromb Vasc Biol 1999, 19:2094-2104.

24. Pfützner A, Schneider CA, Forst T: Pioglitazone: an antidiabetic drug with cardiovascular therapeutic effect. Expert Re Cardiovasc Ther 2006, 4:445-459.

25. Gautier EL, Chow A, Spanbroek R, Marcelin G, Greter M, Jakubzick C, Bogunovic M, Leboeuf M, van Rooijen N, Habenicht AJ, Merad M, Randolph GJ: Systemic analysis of PPARgamma in mouse macrophage populations reveals marked diversity in expression with critical roles in resolution of inflammation and airway immunity. J Immunol 2012, 189(5):2614-2624.

26. Lea S, Plumb J, Metcalfe H, Spicer D, Woodman P, Fox JC, Singh D: The effect of PPAR-y ligands on in vitro and in vivo models of COPD. Eur Respir J 2013. Published on June 21, 2013 as doi:10.1183/ 09031936.00187812.

27. Asada K, Sasaki S, Suda T, Chida K, Nakamura H: Antiinflammatory roles of peroxisome proliferator-activated receptor gamma in human alveolar macrophages. Am J Respir Crit Care Med 2004, 169(2):195-200. 
28. Li J, Dai A, Hu R, Zhu L, Tan S: Positive correlation between PPAR gamma/ PGC -1alpha and gamma-GCS in lungs of rats and patients with chronic obstructive pulmonary disease. Acta Biochim Biophys $\operatorname{Sin} 2010$, 42(9):603-614.

29. Szanto A, Balint BL, Nagy ZS, Barta E, Dezso B, Pap A, Szeles L, Poliska S, Oros M, Evans RM, Barak Y, Schwabe J, Nagy L: STAT6 transcription factor is a facilitator of the nuclear receptor PPARgamma-regulated gene expression in macrophages and dendritic cells. Immunity 2010, 33(5):699-712.

30. Remels AH, Schrauwen P, Broekhuizen R, Willems J, Kersten S, Gosker HR, Schols AM: Peroxisome proliferator-activated receptor expression is reduced in skeletal muscle in COPD. Eur Respir J 2007, 30(2):245-252.

31. Eun CS, Han DS: Attenuation of colonic inflammation by PPAR gamma in intestinal epithelial cells: effect on Toll-like receptor pathway. Dig Dis Sci 2006, 51(4):693-697.

32. Pace E, Ferraro M, Siena L, Melis M, Montalbano AM, Johnson M, Bonsignore MR, Bonsignore G, Gjomarkaj M: Cigarette smoke increases Toll-like receptor 4 and modifies lipopolysaccharide-mediated responses in airway epithelial cells. Immunology 2008, 124(3):401-411.

33. Karimi K, Sarir H, Mortaz E, Smit JJ, Hosseini H, De Kimpe SJ, Nijkamp FP, Folkerts G: Toll-like receptor-4 mediates cigarette smoke-induced cytokine production by human macrophages. Respir Res 2006, 7(1):66.

34. Budulac SE, Boezen HM, Hiemstra PS, Lapperre TS, Vonk JM, Timens W, Postma DS, GLUCOLD study group, the GLUCOLD study group: Toll-Like Receptor (TLR2 and TLR4) Polymorphisms and Chronic Obstructive Pulmonary Disease. PLoS One 2012, 7(8):e43124.

35. Doz E, Noulin N, Boichot E, Guénon I, Fick L, Le Bert M, Lagente V, Ryffel B, Schnyder B, Quesniaux VF, Couillin I: Cigarette smoke-induced pulmonary inflammation is TLR4/MyD88 and IL-1R1/MyD88 signaling dependent. $J$ Immunol 2008, 180(2):1169-1178.

36. MacRedmond RE, Greene CM, Dorscheid DR, McElvaney NG, O'Neill SJ: Epithelial expression of TLR4 is modulated in COPD and by steroids, salmeterol and cigarette smoke. Respir Res 2007, 8(1):84.

37. Giarratano A, Ferraro M, Bruno A, Siena L, Mangione S, Johnson M, Gjomarkaj M: TLR4 upregulation underpins airway neutrophilia in smokers with chronic obstructive pulmonary disease and acute respiratory failure. Hum Immunol 2011, 72(1):54-62.

38. Eun CS, Han DS, Lee SH, Paik CH, Chung YW, Lee J, Hahm JS: Attenuation of colonic inflammation by PPARgamma in intestinal epithelial cells: effect on Toll-like receptor pathway. Dig Dis Sci 2006, 51(4):693-697.

39. Zhang $X$, Shan P, Qureshi S, Homer R, Medzhitov R, Noble PW, Lee PJ: Cutting edge: TLR4 deficiency confers susceptibility to lethal oxidant lung injury. J Immunol 2005, 175(8):4834-4838.

40. Wolfrum C, Borrmann CM, Borchers T, Spener F: Fatty acids and hypolipidemic drugs regulate peroxisome proliferator-activated receptors $a$ - and $\gamma$-mediated gene expression via liver fatty acid binding protein: a signaling path to the nucleus. Proc Natl Acad Sci USA 2001, 98(5):2323-2328.

41. Schachtrup C, Scholzen TE, Grau V, Luger TA, Sorg C, Spener F, Kerkhoff C: L-FABP is exclusively expressed in alveolar macrophages within the myeloid lineage: evidence for PPAR a-independent expression. Int $J$ Biochem Cell Biol 2004, 36(10):2042-2053.

42. Lee MY, Lee EY, Lee BJ, Won CS, Koh JH, Shin JY, Shin YG, Cho BP, Chung $\mathrm{CH}$ : Beneficial effects of thiazolidinediones on diabetic nephropathy in OLETF rats. Yonsei Med J 2007, 48(2):301-307.

43. Ahn KO, Lim SW, Yang HJ, Li C, Sugawara A, Ito S, Choi BS, Kim YS, Kim J, Yang CW: Induction of PPAR gamma mRNA and protein expression by rosiglitazone in chronic cyclosporine nephropathy in the rat. Yonsei Med J 2007, 48(2):308-316.

44. Guo Z, Qin Z, Zhang R, Li J, Yin Y: Effect of rosiglitazone on the expression of cardiac adiponectin receptors and NADPH oxidase in type 2 diabetic rats. Eur J Pharmacol 2012, 685(1-3):116-125.

doi:10.1186/1465-9921-15-28

Cite this article as: Yin et al:: PPAR Gamma agonists regulate tobacco smoke-induced toll like receptor 4 expression in alveolar macrophages. Respiratory Research 2014 15:28.

\section{Submit your next manuscript to BioMed Central and take full advantage of:}

- Convenient online submission

- Thorough peer review

- No space constraints or color figure charges

- Immediate publication on acceptance

- Inclusion in PubMed, CAS, Scopus and Google Scholar

- Research which is freely available for redistribution

Submit your manuscript at www.biomedcentral.com/submit
C Biomed Central 